\title{
Virtual labs versus hands-on labs for teaching and learning computer networking: A comparison study
}

Shimba, Martin

Sokoine University of Agriculture, Tanzania (martinshimba@gmail.com)

Mahenge, Michael P. J.

Sokoine University of Agriculture, Tanzania (mahenge@suanet.ac.tz)

Sanga, Camilius A.

Sokoine University of Agriculture, Tanzania (sanga@suanet.ac.tz)

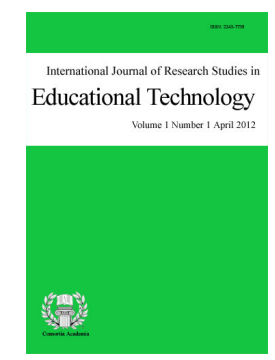

ISSN: $2243-7738$

Online ISSN: 2243-7746

OPEN ACCESS

\section{Abstract}

The purpose of this study was to determine the effectiveness of simulation approach (virtual labs) versus hands on labs approach for teaching and learning computer networking skills in Higher Learning Institutions in Tanzania. The study was conducted at Sokoine University of Agriculture. The theoretical framework which guided this study is Experiential Learning Theory. Experiments were conducted involving configuring Virtual LAN using simulation and hands on Lab approach for teaching and learning. The experiment involved control group and experimental group. In a control group students were taught using Hands on Lab approach while in experiment group students were taught using Simulation approach. In a control group, students were able to configure VLAN and verify or troubleshoot the connection while in the experimental group students configured VLAN with difficulty and failed to verify the connection. From the analysis of data obtained from instructors, it was found that simulation approach is used to a greater extent compared to hands on labs. The reason for this is because of the shortage of tools and hence, instructors rely mostly on the use of simulation approach. Furthermore, students considered both simulation and hands on lab approaches as useful teaching methods to enhance teaching and learning of computer networking skills. Students preferred hands on lab approach to be used over simulation approach due to different reasons including: hands on lab approach enables students to acquire practical or concrete skills and problem solving skills compared to simulation approach. Therefore from the results of this study, hands on lab approach is more effective for imparting practical and problem solving skills, knowledge and competency to students compared to simulation approach.

Keywords: virtual labs; hands-on labs; learning; teaching; computer networking; comparison 


\section{Virtual labs versus hands-on labs for teaching and learning computer networking: A comparison study}

\section{Introduction}

The use and need of Information and Communication Technology (ICT) in various sector including education is rapidly expanding in many countries and now is seen as major means for expanding education sector across the globe (UNESCO, 2006). ICT has been argued to be providing better way to improve teaching and learning in Higher Learning Institutions (HLI) in developing countries (Sife, Lwoga, \& Sanga, 2007). Tanzania has been investing in integrating ICT in education at various levels for decades (Tedre, Bangu, \& Nyagava, 2009; Mwalongo, 2011). The evidence of this fact is that the first ICT courses in Tanzania was started by the University College Dar es Salaam in 1965 at the Institute of Adult Education, later on computer courses were offered to students in the Faculties of Engineering, Science, Commerce, and Arts and in year 1997, University of Dar es Salaam started a Master course in Computer Science (Mgaya, 1994). Currently, many universities in Tanzania including Sokoine University of Agriculture (SUA) do offer Information Technology (IT) courses where Computer networking is amongst of them.

SUA started officially in 1984 to offer agricultural degree programs and allied science, but IT courses started to be offered in 2000's. It is offered under the Department of Informatics at Solomon Mahlangu Campus (SMC) in Morogoro municipal. At SUA, computer networking as a course is offered at different levels from Certificate and Diploma in IT to undergraduate degree programs like Bachelor of Science in Informatics and Bachelor of Science with Education (Informatics and Mathematics). The modes of teaching and learning computer networking at SUA includes the use of e-learning, simulation software (e.g. Cisco packet tracer), project based learning, problem based learning and the use of actual practical in the laboratory. Dahms and Zakaria (2015) reported that most African universities including SUA have shortage of IT infrastructures and tools like Internet, computers and relevant software. Even though most universities has limited IT infrastructure and thus, students do not practice enough hands on lab but simulation approach can complement this discrepancy (Janitor, Frantisek, \& Karol, 2010).

Hands on lab are the learning experience by which learner interact with materials or secondary data to observe, investigate and understand the natural world (Lunetta, Hofstein, \& Clough, 2007). Tedre, Bangu, and Nyagava (2009) emphasize on focusing on developing practical skills to students in HLI of Tanzania rather than emphasizing on theoretical IT curriculum which results into graduates who cannot bring changes and innovations to the society. Dillon (2008) argues that practical work in lab is central to the process of teaching and learning science subjects. Also, Dillon (2008) argue that good quality practical work helps students' to develop understanding of scientific processes and concepts, stimulate and maintain interests in learning, and develop critical and logical thinking. The recommendation by Dillon (2008) is supported by Sarkar (2006) who argue that students learn more effectively from courses involving practical activities than those involving use of simulation software. The use of simulation software involves classroom modeling of computer networks so as to illustrate the theoretical aspects of computer networking before simulation of the model (Davis, Ransbottom, \& Hamilton, 1998). Coffman (2006) emphasize the essence of integration of computer simulation in teaching and learning. She noted that computer simulation provide chances for learners to mirror the real world ideas or environment. The advantages of this approach is that it serves as a technique for enhancing learning by increasing student's interest and awareness in the topic being taught. Also, it is a teaching tool which provides students with realistic experience.

Different authors advocates teaching and learning of computer networking using any approach between simulation software and actual practical. There is a need to conduct a study to investigate the effectiveness of simulation versus actual practical in teaching and learning of computer networking. The aim of both approaches 
Virtual labs versus hands-on labs for teaching and learning computer networking: A comparison study

is to ensure that students acquire practical computer networking skills, knowledge and competency (SKC).

The objective of this study is to investigate the effectiveness of the hands on lab versus simulation approaches in teaching and learning computer networking. Specifically, the study answered the following research questions:

$>\quad$ What are the learners and instructors attitudes when teaching and learning computer networking using hands on lab and simulation approaches?

$>\quad$ To what extent simulation and hands on lab approaches are used in teaching and learning of computer networking?

$>\quad$ What are the merits of using hands on lab versus simulation approaches in teaching and learning of computer networking?

\subsection{Theoretical framework}

Experiential Learning Theory (ELT) is used as a theoretical framework for conducting this study. ELT can be defined as the process whereby the knowledge is created through the transformation of experience (Kolb, 1984). This theory integrates the works of different experiential learning scholars like Lewin, Piaget, Dewey, Frere, and James who proposed a holistic model for learning process (Passarelli \& Kolb, 2012). ELT is grounded on six propositions. These propositions are described below. Learning is best considered as a process not in terms of outcomes meaning that in order to improve learning in higher education, the primary focus should base on engaging students in a process to enhance their learning (Kolb \& Kolb, 2008). All learning is re-learning meaning that individual constructs make sense from their experience. Learning requires the resolution of conflicts between dialectically opposed modes of adaptation to the world. This means that conflicts and differences drive learning (Kolb \& Kolb, 2008). Learning is holistic process of adaptation. This means that learning encompasses thinking, feeling and perceiving learning results from synergetic transaction between the person and the environment. Finally, learning is the process of creating knowledge and not knowledge transmission (Kolb \& Kolb, 2008).

The ELT suggests an idealized learning cycle where different learners touch all bases. Knowledge results from the combination of grasping and transforming experience (Kolb, 1984). The ELT model portrays two dialectically related modes of grasping experience which are Concrete Experience (CE) and Abstract Conceptualization (AE) (Kolb, 1984). Also, the model describes two dialectically related modes of transforming experience which are Reflective Observation (RO) and Active Experimentation (AE). ELT is a cyclic process where a learner gain concrete experience, observe and reflect, forms abstract concept and tests the concepts in a new situations. Thus, the interest of this study is whether experiential interaction with simulation software or experiential interaction with real practical is an effective teaching method in instilling practical computer networking SKC to students. These concepts are illustrated below with reference to this study (see Figure 1).

\section{Literature review}

Teaching and learning of IT courses in developing countries have been reported to be poor (Mtebe \& Kisaka, 2016) and affecting the quality of graduates. This is caused by a number of factors including: shortage of well trained personnel and instructors, misguided policies, outdated curricula, majority of instructor use behaviorism pedagogical teaching approach and also, theoretically imported IT curricula which are not contextualized as per local environment (Mgaya, 1994; Lampi, 2013; Tedre, Bangu, \& Nyagava, 2009; Dahms \& Zakaria, 2015; Mtebe \& Kisaka, 2016). Therefore, theoretically oriented education in developing countries including Tanzania affects the capability of the graduates when they will be employed in different fields like agriculture, ICT and engineering (Tedre, Bangu, \& Nyagava, 2009). This calls for a need to prevent these failures of HLI in Tanzania and other developing countries by emphasizing practical skills to students over theoretical based education 
(Tedre, Bangu, and Nyagava, 2009).



Figure 1. Experiential Learning cycle adapted from Kolb and Kolb (2008, p. 6)

\subsection{Real practical in learning and teaching of computer networking}

The use of real practical approach to teaching and learning of computer networking has been explained by different authors (Sarkar, 2006; Dillon, 2008). The study about "Teaching computer Networking fundamentals using practical laboratory exercises" by Sarkar found that students learn more effective from courses that provide practical activities like configuring and installing server (Sarkar, 2006). Also, Sarkar (2006) found that different computer network simulators exist which can be used in teaching and learning computer networking through building various computer network models. Nevertheless by setting up and configuring actual computer networks students gain hands on or concrete experience which cannot be gained through the use of computer network simulators. Also, Nedic, Machotka, and Nafalski (2003) argue that though there are different software packages which are useful for simulation of real experiments but students learn more effectively from courses involving practical activities (Sarkar, 2006). According to Dillon (2008) the reasons why practical hands are more interested by students is that: (i) it creates interest to learners (ii) It helps learners to develop critical and logical thinking (iii) it helps learner understand easily the scientific processes, concepts and phenomena.

\subsection{Simulation software in learning and teaching of computer networking}

According to Karanja (2012), the power of ICT in improving teaching and learning in East Africa HLI is well recognized. Karanja identified different ICT tools including virtual laboratories which facilitate effective 
means for classroom instruction and provision of laboratory services. Also, Lampi (2013) argue that over the last decade there is an increased trend of using computer based technologies (e.g. virtual lab) in fostering students' learning of scientific and vocational skills where virtual lab. Virtual lab is similar to what Sanga, Magesa, and Tumbo (2005) termed it as virtual experiment. The study by Sanga et al. explain further that in most developing countries there is acute shortage of training equipment which necessitates the adoption of virtual laboratories to complement approaches for teaching and learning computer networking. Also, combination of simulation technology and face-to-face teaching in computer network teaching can effectively help students understand abstract theories which are hard to be understood practically (Janitor et al., 2010). According to Coffman (2006), the integration of simulation in teaching and learning provides chances for learners to mirror the real world ideas or environment. Also, it serves as a technique for enhancing learning and increase student's interest and awareness in the topic being taught. Furthermore, the study by Galán, Fernández, Ruiz, Walid, and De Miguel (2004) suggest the use of real practical and simulation or virtualization tools in teaching and learning of computer networking. The use of virtualization tools minimizes need for equipment and management costs compared to real practical teaching. The future of virtualization tools is on remote laboratory or weblab (Costa, 2014).

\subsection{Reviews on the Research Methodology}

Different studies conducted have applied different research designs. The study by Sarkar (2008) about "Teaching Computer Networking Fundamentals Using Practical Laboratory Exercises" presented the use of practical and its overall effectiveness in teaching and learning of computer networking. The study explored both qualitative and quantitative research methods. Sarkar's study was designed by having practical laboratory exercise for undergraduate students taking computer networking course. The course was assessed quantitatively by evaluating the performance of students in their final exam. Also, students were assessed qualitatively by asking five questions related to their prior knowledge, how easy did they find the laboratory exercises to use and follow, and how effective were the laboratory exercises in helping them to improve their understanding of computer networking. The findings from Sarkar's study show positive impact of using practical to teaching and learning of computer networking.

Also, study by Lampi (2013) on the effectiveness of using virtual laboratories at the University of Zambia applied quantitative research method. This study measured the effectiveness of using virtual laboratories in terms of speed and accuracy of configuration and troubleshooting. The study found that practicing configuration of computer networks in a virtual lab positively improved students' ability to accurately configure real computer networking equipment. While, in another study conducted by Matthews (2005) on the "Hands-on Approach to Teaching Computer Networking Using Packet Traces" applied different sets of simulation experiments. The study found that exercises based on computer network packet tracer to be an excellent addition to computer networking courses for students of all levels. The use of packet tracer add a hands-on skills and practical learning style to students without the need to use specialized computer networking equipment for laboratory exercises.

Different studies conducted earlier applied different theories as the foundation of their studies but other previous studies were not grounded in any theory. For example, Lampi's study applied experiential learning theory as the theoretical framework to measure if experience in a virtual lab by students can be transferred to the real practical. The results obtained showed that the use of virtual labs by students contributes positively to the transfer of practical computer networking skills from the virtual to the real lab environment (Lampi, 2013).

Literature review from this paper indicate that some scholars in their studies support teaching and learning of computer networking using actual practical in laboratories, while other scholars supports the use of simulation software in the teaching and learning of computer networking. Also, other scholars advocate the use of both approaches to maximize the strength of each and minimize the weakness of each approach. Thus, there is a need to conduct study for further investigation on the effectiveness of simulation versus practical approach in teaching and learning of computer networking in context of Developing Countries University. 


\section{Research methodology}

\subsection{Research approach and design}

This study adopted mixed research approach which is the paradigm that combines qualitative and quantitative approaches (Creswell, 2003). The use of mixed approach in this study aimed at helping informing the results of one method with the results from the other approach and also, measuring objectives which could not be obtained by using one method only (Greene, Caracelli, \& Graham, 1989). Quantitative research is based on measurement of quantity where a process is expressed or described in terms of quantities while qualitative approach research is concerned with subjective assessment of attitudes, opinions and behavior (Kothari, 2004).

The first case study in this research used quantitative approach where experimental design was used. In this design, there were two groups involved in the study; control group (students taught computer networking without simulation) and experimental group (students taught computer networking using simulation approach). A simple experiment was designed which involved configuring two Virtual Local Area Network (VLAN) to one switch with two stations (two computers, in the VLAN), the IP address that was used is class C private address as shown in Figure 2 and Table 1.

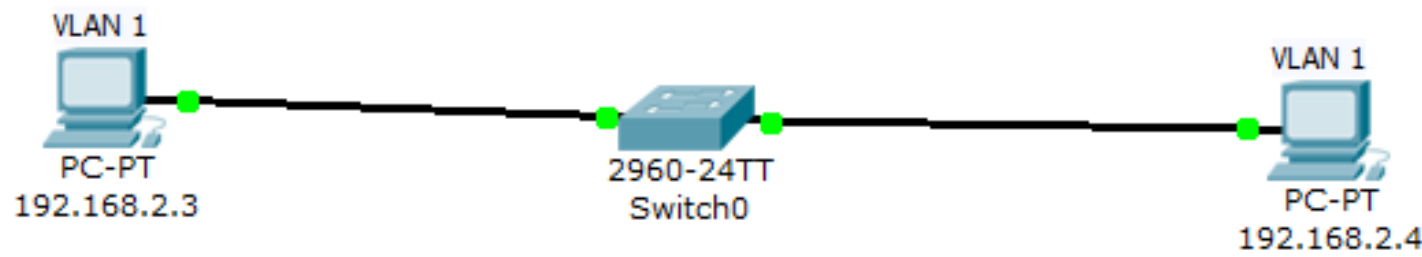

Figure 2. Two VLAN's to be configured using one switch with two devices

Table 1

IP addresses assigned to devices in a VLAN

\begin{tabular}{|c|c|c|}
\hline Device & IP address & VLAN name, VLAN number \\
\hline PC-1 & 192.168.1.183 & AGRICULTURE, 2 \\
\hline PC-2 & 192.168.1.169 & AGRICULTURE, 2 \\
\hline
\end{tabular}

In this investigation, students in the experimental group were taught about configuring VLAN using simulation software called Cisco Packet Tracer 5.3.2, and students in the control group were taught about configuring VLAN using real or physical devices. Then students in the experimental group were given a test to assess different skills attained. Likewise students in control group were given test after the lesson. In this design, the dependent variable were practical skills on VLAN configuration using one switch, and independent variables were simulation and Hands on Lab approaches. The confounding variables include different educational level to respondents which was controlled by ensuring equal grouping of respondents according to their education level. This experimental design aimed at investigating on the benefits of using actual practical and simulation software in teaching and learning of computer networking skills. The assessment was done using observation, questionnaires, test after the practical session and short reflection report to each group for the experiment done. In addition, qualitative approach was used to collect and analyze qualitative data from the students'. In this design, ethnography approach was used because the study involved investigating various reactions to the benefits of teaching and learning computer networking, using real practical and using simulation software.

\subsection{Study area}

This study was carried at Sokoine University of Agriculture (SUA) in Morogoro. The study was limited to 
Virtual labs versus hands-on labs for teaching and learning computer networking: A comparison study

students of third year degree program pursuing BSc. Informatics and BSc. with Education (Informatics and Mathematics), certificate and second year diploma in IT of 2015/16. The study was carried in this university because this university offers IT courses where computer networking is amongst of the course which is offered.

\subsection{Target population and Sampling procedure}

The target population for this study was third year students pursuing Bachelor of Science in Informatics (BSc. Informatics), Bachelor of Science Education informatics and mathematics (BSc. Education Informatics and mathematics) and Certificate and second year Diploma in IT (DIT). Simple random sampling was used in selecting respondents where the sample was selected by listing names of students, folding and randomly picking names of students. This technique was selected so as to prevent biasness in the selecting respondents and grouping students in either control group or experimental group.

\subsection{Data collection and analysis research method}

Data was collected using questionnaire, experimentation and observation research methods during laboratory experiment. The questionnaires were used to collect primary data. Both open ended and closed questionnaires were used to collect data related to perceptions and attitudes of students with respect to the use of simulation and actual practical in teaching and learning computer networking. The ethnography method involved while researcher observed and interpreted the phenomena. During laboratory work observation was efficient method to collect the information about the merits of using real practical over simulation. Table 2 summarizes the research methods for data collection:

Table 2

Data collection methods

\begin{tabular}{lcc}
\hline \multicolumn{1}{c}{ Specific objective } & Method & Type of data collected \\
\hline $\begin{array}{l}\text { To examine learners' attitude and perceptions when using simulation } \\
\text { and actual practical's on teaching and learning computer networking. }\end{array}$ & Questionnaire & Quantitative \\
\hline $\begin{array}{l}\text { To examine the extent of the use of Simulation and Hands on lab in } \\
\text { learning and teaching of computer networking. }\end{array}$ & Questionnaire & Quantitative \\
\hline
\end{tabular}

In this study both qualitative and quantitative analysis strategies were employed to analyze the data collected. Qualitative data analysis was analyzed using content analysis in order to derive the meaning from the set of data collected. Content analysis is a qualitative analysis technique which involves careful, detailed, systematic examination and interpretation of a particular body of material in an effort to identify patterns, themes, biases and meanings (Berg, 2007). The quantitative were analyzed using Statistical Package for Social Science (SPSS) where the data were grouped into frequency and distribution table. Table 3 summarizes the data analysis strategies which were used in this study:

Table 3

Data analysis strategies

\begin{tabular}{lcc}
\hline \multicolumn{1}{c}{ Specific objective } & Method & Analysis \\
\hline $\begin{array}{l}\text { To examine learners' attitude and perceptions when using simulation } \\
\text { and actual practical's on teaching and learning computer networking. }\end{array}$ & Questionnaire & $\begin{array}{c}\text { Descriptive } \\
\text { Analysis }\end{array}$ \\
\hline $\begin{array}{l}\text { To examine the extent of the use of simulation software and actual } \\
\text { practical on learning and teaching of computer networking. }\end{array}$ & Questionnaire & $\begin{array}{c}\text { Descriptive } \\
\text { Analysis }\end{array}$ \\
\hline $\begin{array}{l}\text { To examine the merits of using actual practical over simulation } \\
\text { software in teaching and learning of networking }\end{array}$ & $\begin{array}{c}\text { Questionnaire, } \\
\text { Experimentation, \& } \\
\text { Observation }\end{array}$ & $\begin{array}{c}\text { Descriptive } \\
\text { Analysis }\end{array}$ \\
\hline
\end{tabular}

Source: Field data. 
Shimba, M., Mahenge, M. P. J., \& Sanga, C. A.

\subsection{Ethical consideration}

The following ethics were adhered before and during the study. First, permission was granted from authorities to conduct the study at SUA. Also, we obtained informed consent of participants (i.e. ensuring voluntary participation) where the participants involved in the study were invited voluntarily. Furthermore, confidentiality was maintained all the time (i.e. during and after the end of research).

\section{Results and Discussion}

\subsection{Learner's attitude and perceptions when using simulation and Hands on lab on teaching and learning} computer networking

Table 4 presents learner's attitude and perceptions on using simulation and Hands on lab on teaching and learning computer networking skills.

Table 4

Simulation versus Hands on Lab on enhancing learning of networking skills

\begin{tabular}{lcccc}
\hline & \multicolumn{2}{c}{ Simulation } & \multicolumn{2}{c}{ Hands on lab } \\
\cline { 2 - 5 } & Frequency & Percentage (\%) & Frequency & Percentage $(\%)$ \\
\hline Strongly disagree & 6 & 15 & & 2.5 \\
Disagree & 2 & 5 & 1 & 12.5 \\
Undecided & 2 & 5 & 5 & 55 \\
Agree & 20 & 50 & 22 & 5 \\
\hline
\end{tabular}

Source: Field data.

From the findings, $50 \%$ of respondents agreed that simulation enhances learning and teaching of computer networking. On the other hand, 55\% of respondents agreed that Hands on lab enhances learning and teaching of computer networking. These results supports the findings by Lampi (2013) who found that there is performance gain in configuration and troubleshooting when students use either virtual lab or real labs. Also, the results from this study support the findings by DiCerbo, West, Frezzo, Behrens, and Cisco. (2009) who did comparison of virtual lab, real lab and no virtual lab. They discovered that virtual and real lab groups performed significantly better than no virtual group.

\subsection{The extent of the use of simulation and Hands on lab in learning and teaching of computer networking}

The results in Table 5 show the attitudes, perceptions and suggestions provided by the students while determining the approach they use during teaching and learning of computer networking:

\section{Table 5}

The Extent of the Use of Simulation versus Hands on Lab

\begin{tabular}{lcccc}
\hline & \multicolumn{2}{c}{ Simulation } & Hands on lab \\
\cline { 2 - 5 } & Frequency & Percentage (\%) & Frequency & Percentage $(\%)$ \\
\hline Used simulation & 38 & 95 & & \\
Not used simulation & 2 & 5 & 16 & 40 \\
Used hands on lab & & & 24 & 60 \\
Not used hands on lab & & & & \\
\hline
\end{tabular}

Source: Field data.

The results presented in Table 5 indicate that $95 \%$ of respondents agreed that they have used simulation 
Virtual labs versus hands-on labs for teaching and learning computer networking: A comparison study

software while learning and teaching of computer networking. On the other hand, $60 \%$ of the respondents claimed that they have not used Hands on Lab approach while learning and teaching of computer networking.

In this study participants investigated the extent in use of Simulation and Hands on lab during learning and teaching of computer networking. The findings indicate that simulation is used mostly compared to hands on lab approach for learning and teaching of computer networking (Table5). There are a number of reasons why students use simulation mostly compared to Hands on lab approach. These are as listed below by respondents: first, there is a shortage of equipment to be used for Hands on lab approach. This matches the report by Dahms et al. (2015) who reported that most African universities faces the problem of shortage of infrastructures and tools like Internet, computers and relevant software and all these limits the growth of ICT in teaching and learning. Also, the second factor is that instructors do not use Hands on Lab approach while teaching computer networking. This might be caused by the shortage of equipment for Hands on Lab approach. Another reason is the big class size which makes hard to use Hands on Lab approach by instructor.

\subsection{Merits of using Hands on lab versus simulation in teaching and learning of computer networking}

The findings presented in Table 6 indicate that $100 \%$ of the respondents proposed the use of Hands on Lab over simulation in learning and teaching of computer networking. The following are the factors given by respondents why use Hands on Lab approach is better than simulation; first, it enables learners to acquire concrete computer networking skills; second, it facilitates deeper understanding of computer networking skills; third, it motivates students to learn computer networking and also, promotes problem solving skills to learners; fourth, it promotes greater interaction between learners, instructors and computer network experts; and lastly, it promotes creativity and enhance memory retention to learners.

\section{Table 6}

Suggested approach for teaching and learning computer networking skills

\begin{tabular}{lcc}
\hline & Frequency & Percentage (\%) \\
\hline Hands on lab & 40 & 100 \\
\hline Source: Field data. & &
\end{tabular}

During the experiment, the control group (Hands on Lab group) manifested that they acquired skills, knowledge and competency during the lesson. They managed to connect, configure, verify and troubleshoot the configuration. They used less than 30 minutes to complete their assignment. On the other hand, experimental group managed to connect and configure switch in more than 30 minutes. This group failed to verify and troubleshoot configuration. However, the study by Lampi (2003) concluded that virtual lab is an effective tool for teaching computer networking concepts involving configuration and troubleshooting. In this study respondents only interacted with Client Line Interface (CLI) and thus did not participate on connecting real devices. Hence, the finding of this study is in contrary to the previous findings, as simulation approach failed to develop troubleshooting skills to students. Other factors including that hands on lab develop problem solving skills to students, as students may be able to apply the skills acquired during the hands on lab approach into new environment after completion of their studies (i.e. graduation). Also, hands on lab facilitate deeper understanding of computer networking subject.

\subsection{Results from experiment}

Experiment was conducted in order to collect data on the effectiveness of hands on lab approach versus simulation. Virtual Local Area Network (VLAN) was configured in a switch and tested for connection. The experiment involved two groups (control group and experimental group) and the participants of these groups were selected randomly. Nine (9) participants were involved in each group. The participants of the control were taught using hands on lab approach and the experimental groups were taught using simulation software (Cisco 
packet Tracer).

The objective of the experiment was to measure the effectiveness of the two approaches for teaching computer networking. Participants were given different tasks including explaining the meaning of VLAN, identifying the tools to be used to configure VLAN, connect two devices using switch with Ethernet cables configure VLAN by means of switch and verify if the VLAN was correctly configured and working. The Experimental group was taught on VLAN configuration using Cisco packet tracer and the results are presented in Figure 3 and Figure 4.



Figure 3. Simulation configuration (Source: Cisco packet tracer, v5.3.2)

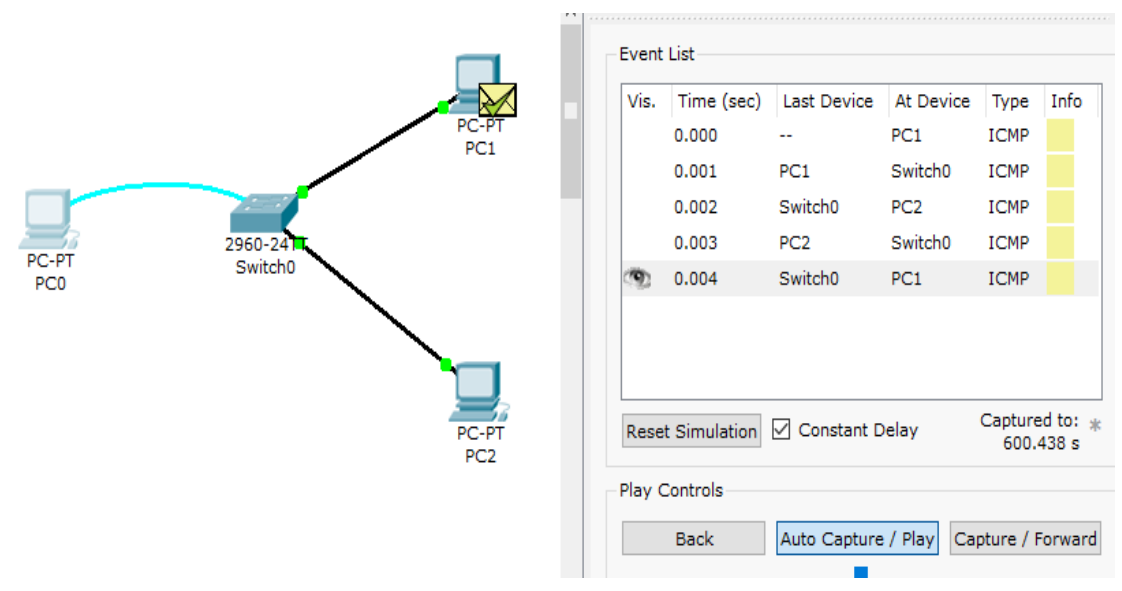

Figure 4. Simulation results (Source: Cisco packet tracer, v5.3.2)

In order to measure the effectiveness of each approach, participants of each group attempted similar test. The test aimed to measure various dimensions of bloom taxonomy including knowledge, understanding, application and synthesis. The results are summarized in Table 7 below:

Table 7

Students Performance in Test between Simulation Group and Hands on Lab Group

\begin{tabular}{llllllllc}
\hline \multicolumn{1}{c}{ Group } & \multicolumn{2}{c}{ Poor } & \multicolumn{2}{c}{ Good } & \multicolumn{2}{c}{ Better } & \multicolumn{2}{c}{ Best } \\
\hline \multicolumn{1}{c}{ Simulation / Hands on lab } & $n$ & $\%$ & $n$ & $\%$ & $n$ & $\%$ & $n$ & $\%$ \\
\hline Meaning of VLAN & 0 & 0 & 5 & 55.6 & 1 & 11.1 & 3 & 33.3 \\
Requirements for configuring VLAN & 0 & 0 & 1 & 11.1 & 1 & 11.1 & 7 & 77.8 \\
How to configure VLAN & 0 & 0 & 2 & 22.2 & 3 & 33.3 & 4 & 44.4 \\
VLAN configuration & 0 & 0 & 9 & 100 & 0 & 0 & 0 & 0 \\
VLAN verification & 9 & 100 & 0 & 0 & 0 & 0 & 0 & 0 \\
\hline
\end{tabular}


Virtual labs versus hands-on labs for teaching and learning computer networking: A comparison study

Table 7 ... continued

\begin{tabular}{lcccccccc}
\hline Meaning of VLAN & 1 & 11.1 & 3 & 33.3 & 1 & 11.1 & 4 & 44.4 \\
Requirements for configuring VLAN & 0 & 0 & 3 & 33.3 & 1 & 11.1 & 5 & 55.6 \\
How to configure VLAN & 1 & 11.1 & 1 & 11.1 & 7 & 77.8 & 0 & 0 \\
VLAN configuration & 0 & 0 & 0 & 0 & 0 & 0 & 9 & 100 \\
VLAN verification & 0 & 0 & 0 & 0 & 0 & 0 & 9 & 100 \\
\hline
\end{tabular}

Source: Experiment data.

Explaining the meaning of VLAN - The findings represented in Table 7 provide evidence that only $11.1 \%$ of respondents in the control group answered poorly (inadequately) the meaning of VLAN while $33.3 \%$ their attempt was good (suitable), $11.1 \%$ attempted better (more acceptable), and $44.4 \%$ attempted the best (better than all others). On the other hand $55.6 \%$ of the respondents from the experimental group suitably explained on the meaning of VLAN, $11.1 \%$ of the respondents attempted better (more acceptable), and $33.3 \%$ attempted the best (better than all others).

List the requirements for configuring VLAN - Similarly on measuring ability to identify requirements for VLAN configuration, $33.3 \%$ of respondents in the control group were able to suitably list the tools for configuring VLAN, 11.1\% were able to list (more acceptably) the tools for configuring VLAN and 55.6\% listed the requirements better than all others. On the other hand, $11.1 \%$ of respondents from experimental group were able to suitably list the tools for configuring VLAN, $11.1 \%$ were able to list (more acceptably) the tools for configuring VLAN and $77.8 \%$ listed the requirements better than all others.

Explain how to configure VLAN - In measuring the technical know-how in VLAN configuration, 11.1\% of the respondents in the control group poorly explained on how to configure VLAN, while another $11.1 \%$ suitably explained how to configure VLAN and $77.8 \%$ of the respondents were more suitably able to explain how to configure VLAN. On the other hand, $22.2 \%$ from experimental group suitably explained how to configure VLAN, $33.3 \%$ were more suitably able to explain how to configure VLAN and $44.4 \%$ were able to explain better than others.

Given all the tools, respondents tasked to configure VLAN - The control group excellently managed to configure VLAN on a Cisco switch given all the devices required for configuration. On the other hand, Table 7 shows that experimental group more suitably managed to configure VLAN on a Cisco switch given all the devices required for configuration.

Verifying the configured VLAN - The control group excellently managed to verify the configured VLAN, through connecting two computers with the switch using Ethernet cables and the VLAN was working properly. However, the experimental group was unable to verify the configured VLAN. Figure 5 and Figure 6 illustrate the test statistics from the experimental and control groups. In Figure 5 devices could not communicate as indicated by destination host unreachable status. Also the group failed to troubleshoot the problem. On the other hand, Figure 6 shows that configuration from control group was working successfully and devices connected were able to communicate.

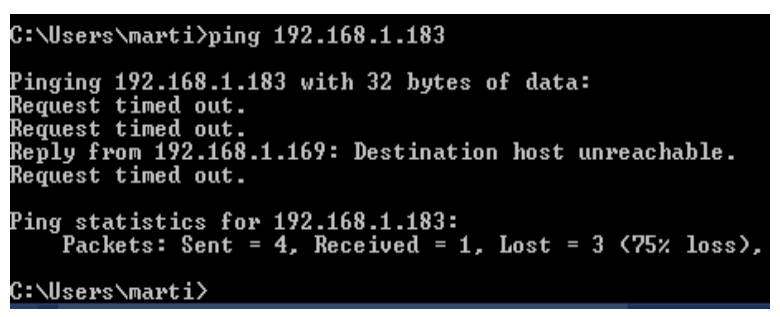

Figure 5. Ping statistics from Experimental group 


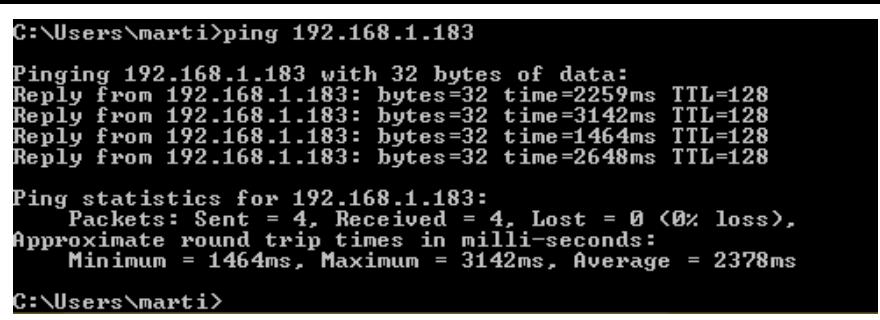

Figure 6. Ping statistics from control group

Summary report of the experiment - The control group wrote a short report, describing how the experiment was conducted. In the report, they explained the purpose of the study, procedures used during configuration and verification of VLAN. Furthermore, they suggested that learning of computer networking skills should be done using hands on lab approach rather than simulation approach. The reason for their suggestion was based on the fact that it is more interactive to learners as students were able to ask questions and configure the VLAN. On the other hand, experimental group recommended that instructors should use hands on lab rather than simulation software in teaching and learning of computer networking skills.

Observation during the experiment - While instructing the configuration of VLAN students were motivated to learn the skills, they could freely ask question about the study and they were easily able to acquire concrete skills. Students managed to configure VLAN and verified in short time (27 minutes). On the other hand, while instructing the configuration of VLAN using Cisco packet tracer to the experimental group, students were motivated to learn the skills, and they could freely ask question about the study. However, when they were required to configure VLAN given all tools during the test they hardly managed. They spent 1 hour to configure VLAN on a switch and lastly they failed to verify the configured VLAN.

\section{Findings}

Three quarter of the responds $(75 \%, 85 \%$ for simulation and Hands on Lab respectively) considered that both hands on lab and Simulation approach enhance teaching and learning of computer networking skills. Also all respondents from each group suggested Hands on lab approach to be used over Simulation approach because Hands on Lab enable learners to acquire concrete computer networking skills and problem solving skills. Furthermore, $95 \%$ of the respondents claimed that, they have been using simulation software in teaching and learning of computer networking skills while only $40 \%$ claimed that they have been using Hands on lab approach for teaching and learning computer networking skills. Low rate of using hands on lab is due to the shortage of equipment to facilitate teaching computer networking skills. However, using simulation approach rather than hands on lab is due to the big class size and time factor for Hands on lab approach.

The study revealed that learners involved in the practical lesson they did well on their own during the practical test. They managed to configure and verify the configuration of VLAN on switch. On the other hand, learners taught using Simulation during the experiment they hardly managed to only configure VLANs but they failed to verify the configuration. From the study $100 \%$ of the respondents suggested Hands on Lab approach to be used for teaching and learning of computer networking skill. Reasons for the suggestion includes that, Hands on lab approach enables learners to acquire concrete computer networking skill, facilitates deep understanding of networking skills, promotes problem solving skills to learners, promotes greater interaction to learners, teachers and computer networking skills and promotes creativity to learners.

\subsection{Relevance of the Experiential Learning Theory in this study}

The study was based on the Experiential Learning Theory (ELT). This theory has 5 different key concepts which are; the cycle of learning from experience, learning styles like diverging and converging styles, learning spaces, learning flexibility, and the experiential learning theory of development. This study employed the cycle of learning from experience. Figure 1 presented these cycle of learning and how they guided in this study. 
Virtual labs versus hands-on labs for teaching and learning computer networking: A comparison study

Considering the concept of cycle of learning from experience, Kolb (1984) described experiential learning as a cyclic process of gaining concrete experiences, observing and reflecting, forming abstract concepts, and testing these concepts in new situations where is expected to touch all the basis for effective learning. ELT explains learning as the process whereby knowledge is created from transformation of experience. Knowledge results from the combination of grasping ( $\mathrm{CE}$ and $\mathrm{AC})$ and transforming experience ( $\mathrm{AE}$ and $\mathrm{RO}$ ) where Grasping experience means the process of taking in information, and transforming experience is how individuals interpret and act on that information (Kolb, 1984). Thus using the concept of learning cycle, Simulation and Hands on lab were evaluated. The results are shown in Table 3 up to Table 7. Also, Figure 3 up to Figure 7 shows also the results from this study.

Staring with CE, in this study two approaches of Simulation and Hands on Lab were employed so as to instill concrete experience (VLANs configuration on a Cisco switch) to learners. The experiences instilled to learners were expected to form a basis for Reflection and Observation according to ELT. Following the CE is RO where this part involves learners stepping back from the task and reviewing what has been done and experienced, for example learners can report on what is experienced. In this study, learners where asked to report on what they have done, during the practical. Therefore learners reported on what they did and they provided suggestions and recommendation in accordance to what they were involved in their respective groups.

After RO learners are expected to be able to develop abstract concepts (AC), where a learner can make sense of what has happened which involves interpreting the events and understanding the relationships between them. In this concept during the study, learners were expected to be able to give relationship between various concepts in the practical and to be able to explain various concepts relating to the study. Then the fourth stage is $\mathrm{AE}$ where we expect learners to be able to translate the concepts conceptualized during simulation or real practical to solve real (actual) problems. And from active experimentation the cycle is continuous where the implications from the study, serves a guide for creating new experiences. Therefore following the ELT concept of learning cycle, the two approaches of teaching and learning computer networking skills (Simulation and Hands on lab) were evaluated, and it was found out that learners involved in the Hands on lab approach (control group) surpassed learners involved in Simulation approach (Experimental group) in the phases of AE and RO explained in ELT. This was due the fact that, learners in Experimental group proved to have managed to effectively reflect on the concrete experiences acquired during CE phase and applied the concepts learned into new environment, where learners in Experimental group failed to perform better in AE and RO stages of ELT. Thus using concept of cycle of learning experience in ELT, there is evidence that Hands on lab approach is better for instilling concrete skills and problem solving skills to learners.

\section{Conclusion and recommendations}

The purpose of this study was to determine the effectiveness of using Hands on lab approach versus Simulation approach in teaching and learning of computer networking skills. The study involved the collection of views of respondents using questionnaire tool followed by simple experiment (which involved VLAN configuration and testing if it is working). This study has basis on the Experiential Learning Theory by Kolb (1994). The ultimate goal of the experiments set in this study were to determine whether students taught using Hands on Lab versus Simulation could transfer the knowledge acquired using either approach into practical environment.

The following conclusions are made basing on the findings of this study.

> Hands on lab approach and simulation approach are both considered for enhancing teaching and learning of computer networking skills however Hands on lab is suggested to be used for enhancing practical computer networking skills and problem solving computer networking skills.

$>$ Hands on Lab approach is less used for teaching and learning of computer networking skills due to factors like shortage of tools for Hands on lab, less emphasis from instructors on the use of the 
approach, as they rely much on Simulation and big class size which makes hard to use Hands on lab approach. As in this study more than $90 \%$ of the respondents argued that they have been using Simulation software while only $40 \%$ of the respondents argued that they have been using Hands on Lab approach when teaching and learning computer networking skills.

Hands on Lab approach enables learners to acquire more on practical and problem solving skills like configuration and troubleshooting skills. This is due to the fact that learners involved in the practical lesson they managed to configure and verify the VLAN configuration.

$>$ Simulation approach enables learners to acquire less of practical skills and problem solving skills. As learners involved in Simulation approach were able to configure VLAN with difficulty, also they failed to troubleshoot and verify the configuration due to the limited practical knowledge.

\subsection{Recommendations}

Based on conclusions of this study, the following recommendations are being made.

$>$ There should be strong emphasis from the High learning institutions Administration to the use of Hands on lab approach rather than simulation software for teaching and learning computer networking courses and other courses for BSc Informatics, BSc Computer Science and other related degree courses. The reason for this is that students need practical skills for applying in the working areas which can be greatly found using Hands on Lab approach. To effectively implement this, there is a need to include in the curriculum the learning objectives and learning outcomes which emphasis the application of this approach by the administration and instructors while teaching computer networking.

$>\quad$ There should be strong measure to acquire tools necessary for implementing Hands on Lab approach in the Higher learning institutions. This can be achieved by raising funds through seeking grants and aids from Government and from other educational stakeholders.

$>$ Effective use of the few available tools for Hands on lab approach, which can at least ensure students get a chance to be exposed in the true practical computer networking skills before graduating from Higher learning institutions.

$>$ Instructors for courses in BSc Informatics which require practicals should adopt teaching methods which imparts competencies. The examples of these methods are problem based learning, project based learning, experiential based learning etc.

> Government of Tanzania should enforce educational policies to foster practical learning in Higher learning institutions. This should go together with the allocation of funds for assisting the Higher learning institutions to achieve this goal.

\section{References}

Anisetti, M., Bellandi, V., Colombo, A., Cremonini, M., Damiani, E., Frati, F., \& Rebeccani, D. (2007).Learning computer networking on open para virtual laboratories. IEEE Transactions on Education, 50(4), 302-311. https://doi.org/10.1109/TE.2007.904584

Berg, B. L. (2007). Qualitative research methods for social sciences. Boston: Pearson Education Inc.

Coffman, T. (2006). Using simulations to enhance teaching and learning: Encouraging the creative process. Virginia Society for Technology in Education Journal, 21(2), 1-7.

Costa, R. (2014). An IEEE1451.0-compliant FPGA-based reconfigurable weblab (Unpublished doctoral dissertation). Information Sciences and Technologies, Department of Informatics Engineering Faculty of Science and Technology, University of Coimbra, Portugal. 
Virtual labs versus hands-on labs for teaching and learning computer networking: A comparison study

Dahms, M. L., \& Stentoft, D. (2008). Does Africa need problem based learning? Educational change in engineering education. Paper presented at American Society of Engineering Education (ASEE) - Global Colloquium, Cape Town, South Africa.

Dahms, M.-L., \& Zakaria, H. L. (2015). Institutional capacities in E-learning and problem based learning at universities and university colleges in Tanzania and Ghana. Department of Development and Planning, Aalborg University.

Davis, N., Ransbottom, S., \& Hamilton, D. (1998). Teaching computer networks through modeling. ACM SIGAda Ada Letters, 18(5), 104-110. https://doi.org/10.1145/291712.291758

DiCerbo, K. E., West, P., Frezzo, D., Behrens, J. T., \& Cisco, I. R. C. C. (2009). Experimental exploration of a complex simulated environment. Unpublished manuscript. Retrieved from https://research.netacad.net/file.php/1/moddata/data/1/11/17/Simulation_Experiment.pdf

Dillon, J. (2008). A review of the research on practical work in school science. Kings College, London.

Dobrilovic, D., \& Odadzic, B. (2006). Virtualization technology as a tool for teaching computer networks. World Academy of Science, Engineering and Technology, 13, 126-130.

Galán, F., Fernández, D., Ruiz, J., Walid, O., \& De Miguel, T. (2004, June). Use of virtualization tools in computer network laboratories. In the Proceeding of 5th international conference on information technology based higher education and training (pp. 209-214). https://doi.org/10.1109/ithet.2004.1358165

Janitor, J., Frantisek, J., \& Karol, K. (2010). Visual learning tools for teaching/learning computer networks. Paper presented on sixth international conference on networking and services. In the $6^{\text {th }}$ international conference on networking and services. http://dx.doi.org/10.1109/ICNS.2010.55

Karanja, T. (2012). ICT in East African education: The inescapability dilemma. Kenya.

Kolb, A. Y., \& Kolb, D. A. (2009). Experiential learning theory: A dynamic, holistic approach to management learning, education and development. In S. J. Armstrong \& C. V. Fukami (Eds.), The SAGE handbook of management learning, education and development (pp. 42-69). London: SAGE. http://dx.doi.org/10.4135/9780857021038.n3

Kolb, D. A. (1984). Experiential learning: Experience as the source of learning and development. Englewood Cliffs, NJ: Prentice-Hall.

Lampi, E. (2013). The effectiveness of using virtual laboratories to teach computer networking skills in Zambia (Unpublished doctoral dissertation). Virginia Polytechnic Institute and State University, Virginia, USA.

Lan, C. H. (2007). Book review: Tools for teaching computer networking and hardware concepts. Educational Technology \& Society, 10(1), 268-270.

Lunetta, V. N., Hofstein, A., \& Clough, M. P. (2007). Teaching and learning in the school science laboratory: An analysis of research, theory, and practice. In S. K. Abell \& N. G. Lederman (Eds.), Handbook of research on science education (pp. 393-431). Mahwah, NJ: Lawrence Erlbaum Associates.

Lyons, J. (2012). Learning with technology: Theoretical foundations underpinning simulations in higher education. Retrieved from http://www.ascilite.org/conferences/Wellington12/2012/images/custom/lyons,_judith___learning.pdf

Marsic, I. (2013). Computer networks: Performance and quality of service. New Jersey: Rutgers University.

Matthews, J. N. (2005). Hands-on approach to teaching computer networking using packet traces. In the Proceedings of the 6th conference on information technology education (pp. 361-367). ACM.

McHaney, R. (2009). Understanding computer simulation. Ventus Publishing.

Mgaya, K. (1994). Development of information technology in Tanzania. In E. P. Drew \& F. G. Foster (Eds.), Information technology in selected countries (pp. 334-347). Tokyo, Japan: The United Nations University.

Mwalongo, A. (2011). Teachers' perceptions about ICT for teaching, professional development, administration and personal use. International Journal of Education and Development using Information and Communication Technology, 7(3), 36-49.

Nedic, Z., Machotka, J., \& Nafalski, A. (2003). Remote laboratories versus virtual and real laboratories. Retrieved from http://www.discoverlab.com/References/1077.pdf https://doi.org/10.1109/fie.2003.1263343

Passarelli, A., \& Kolb, D. A. (2012.). Using experiential learning theory to promote student learning and development in programs of education abroad. Retrieved from https://weatherhead.case.edu/departments/organizational-behavior/workingPapers/WP-11-03.pdf 
Shimba, M., Mahenge, M. P. J., \& Sanga, C. A.

Sanga, C., Magesa, M., \& Tumbo, S.D. (2005). Agricultural systems simulation I (R8088A). Module 1. In S. D. Tumbo \& H. F. Mahoo (Eds.), A manual for virtual experiments in agriculture: The use of

PARCHED-THIRST software in agricultural systems simulations (p. 16). Morogoro, Tanzania: Sokoine University of Agriculture.

Sarkar, N. I. (2006). Teaching computer networking fundamentals using practical laboratory exercises. IEEE Transactions on Education, 49(2), 285-291. https://doi.org/10.1109/TE.2006.873967

Sife, A., Lwoga, E., \& Sanga, C. (2007). New technologies for teaching and learning: Challenges for higher learning institutions in developing countries. International Journal of Education and Development using ICT, 3(2).

Tedre, M., Bangu, N., \& Nyagava, S. (2009). Contextualized IT education in Tanzania: Beyond standard IT curricula. Journal of Information Technology Education Research, 8(1), 101-124.

UNESCO. (2006). ICT in Education .Retrieved from http://en.unesco.org/themes/ict-education

Vogel, J. J., David, S. V, Jan, C. B., Clint, A. B, Kathryn, M., \& Michelle, W. (2006). Computer gaming and interactive simulations for learning: A meta-analysis. Journal of Educational Computing Research, 34(3), 229-243. https://doi.org/10.2190/FLHV-K4WA-WPVQ-H0YM 